\title{
A serological method for distinguishing coagulase- negative staphylococci from micrococci
}

\author{
L. S. NAKHLA
}

From the Cross-Infection Reference Laboratory, Colindale, London

SYNOPSIS Absorbed antisera prepared against heat-killed suspensions of a coagulase-negative staphylococcus and of a micrococcus were used in a slide-agglutination test. A collection of 176 coagulase-negative aerobic cocci, from which Staphylococcus aureus had been excluded, was classified into staphylococci and micrococci by means of the test for anaerobic utilization of glucose. Of 113 staphylococci, 99 reacted with the anti-staphylococcus serum, seven with the micrococcus serum, and seven with neither; of 63 micrococci, 55 reacted with the micrococcus serum and eight were untypable. Thus 161 of 176 strains $(91 \%)$ were classifiable serologically, and in 154 of 161 instances $(95 \%)$ the results of the serological and biochemical classification were in agreement.

The distinction between coagulase-negative staphylococci and micrococci is becoming increasingly important as certain types of these organisms are implicated in a variety of clinical conditions, eg, colonization of ventriculo-atrial shunts (Holt, 1969, 1972), endocarditis, particularly after open cardiac surgery (Watanakunakorn and Hamburger, 1970), urinary tract infection (Mabeck, 1969; Mortensen, 1969), conjunctivitis (Nakhla, Al-Hussaini, and Shokeir, 1970), and meningitis (Public Health Laboratory Service, 1971). Infection with coagulasenegative staphylococci can be acquired in hospitals by cross-infection (Quinn, Cox, and Fisher, 1965). In addition to their role as pathogens coagulasenegative staphylococci may be used as epidemiological markers in studying the dispersion of bacteria in the hospital environment. A phage typing system for these staphylococci is now available (Verhoef, Van Boven, and Winkler, 1971a and b, 1973; Dean, Williams, Hall, and Corse, 1973). Mainly staphylococci, particularly those belonging to Baird-Parker subgroup II (Baird-Parker, 1963), are susceptible to these phages. Only a small proportion of micrococci are typable. It is therefore important before typing these organisms to exclude micrococci if a high proportion of typability is to be expected. The only test generally used to distinguish between the two genera is that which determines the ability of

${ }^{1}$ Present address: Senior Registrar in Bacteriology, Westminster Hospital Teaching Group, Queen Mary's Hospital, Roehampton, London, SW15

Received for publication 30 April 1973. staphylococci to ferment with acid production glucose anaerobically and the failure of micrococci to do so (Evans, Bradford, and Niven, 1955; BairdParker, 1963). This test, when done by the method recommended by the subcommittee on the taxonomy of staphylococci and micrococci (International Bulletin of Bacteriological Nomenclature and Taxonomy, 1965), does not give a result before five days' incubation. Furthermore, the results of the test are sometimes not clear-cut (Chalmers, 1972) and consequently their interpretations differ from one laboratory to another. In some strains the results are also inconsistent on repeated testing. After using this test on several hundreds of strains we think that the difference between staphylococci and micrococci in fermenting glucose under anaerobic conditions is in the amount of acid produced rather than an absolute all-or-none difference. This observation has also been reported by Mortensen (1969) on a number of strains isolated from cases of urinary tract infection. All the strains he isolated produced a certain degree of acid from glucose anaerobically. They differed only in the amount of acid produced as determined by accurate measurement of the final $\mathrm{pH}$ of the medium. The group of organisms that produced less acid when tested by the conventional biochemical test would have been, in the opinion of the author, classified as micrococci.

For the busy clinical bacteriologist with heavy routine commitments and the epidemiologist and research worker dealing with a large number of strains a test is needed to distinguish between coagulase-negative staphylococci and micrococci 
with reasonable accuracy and involvement of less material and time. This paper describes an attempt to achieve this by the use of a simple serological test. There are known antigenic differences between staphylococci and micrococci, especially the content of the cell walls of different classes of teichoic acid (Morse, 1963; Davison and Baddily, 1964; Baddily, Brock, Davison, and Partridge, 1968; Grov and Helgeland, 1971). It is such differences which may underlie any possible success in the use of serological tests for distinguishing these two classes of organisms.

\section{Materials and Methods}

\section{STAPHYLOCOCCI AND MICROCOCCI}

\section{Vaccine strains}

Three strains were selected for preparation of antisera: a Staph. aureus (no. 71/763), a micrococcus (no. 71/764), and a Staph. epidermidis belonging to Baird-Parker (1963) subgroup II (no. 71/781). The first two were isolated from the uniform of nursing staff at Clare Hall Hospital and the third from the nose of a nurse in the same hospital. On repeated testing (three times) these strains gave clear-cut results of biochemical tests, particularly the anaerobic fermentation of glucose.

\section{Strains of staphylococci and micrococci tested}

A total of 176 strains of coagulase-negative staphylococci and micrococci were used in this study. The sources of them were as follows: (1) cultures of nasal swabs of healthy hospital staff (61 strains); (2) urine cultures of patients with urinary tract infection (41 strains), kindly supplied by Dr $\mathbf{M}$. Mortensen, the State Serum Institute, Copenhagen, Denmark; (3) blood and cerebrospinal fluid cultures of cases of bacteraemia following ventriculo-atrial shunt operations (30 strains), kindly supplied by Dr R. J. Holt, Queen Mary's Hospital for Children, Carshalton, Surrey, England; (4) routine blood cultures from hospital patients referred for phage typing (44 strains).

All strains were tested by slide agglutination. The first 31 strains of the first group were tested in addition by precipitation (see below).

\section{CULTURE MEDIA}

For preparation of the vaccines and for growing the organisms before serological typing nutrient agar was used. This consisted of Oxoid nutrient broth no. 2 (code no. CM7) solidified by Oxoid agar no. 3 (code no. L13). Nutrient agar prepared from the same Oxoid broth solidified by shredded agar was used for phage typing. Anaerobic fermentation of glucose was tested in the medium recommended by the subcommittee on the taxonomy of staphylococci and micrococci (International Bulletin of Bacteriological Nomenclature and Taxonomy, 1965). Coagulase testing was done by the tube method using $10 \%$ human plasma in nutrient broth.

MEDIUM FOR THE GEL-DIFFUSION PRECIPITATION TEST

This consisted of a $1 \%$ solution of agarose (KochLight Laboratories, Colnbrook, Bucks) in distilled water. The melted medium was first spread in thin layers on the surfaces of clean microslides followed by a second layer of $4 \mathrm{ml}$ of medium on top of the first and left to solidify. Three sets of five wells, $4 \mathrm{~mm}$ apart, were punched out on each slide, one well in the centre surrounded by four wells. The slides were left in the refrigerator at $4 \mathrm{C}$ overnight before use.

R A B B I T S

Mixed breed rabbits weighing 3-4 k each were used for preparation of antisera.

PREPARATION OF VACCINES

Each vaccine strain was plated on nutrient agar and a single colony subcultured on nutrient broth (Oxoid no. 2) and incubated overnight at $37^{\circ} \mathrm{C}$. Nutrient agar plates $14 \mathrm{~cm}$ in diameter were flooded with the broth cultures, two plates for each vaccine, and the excess was pipetted off. The plates were incubated at $37^{\circ} \mathrm{C}$ for 24 hours. The growth obtained was scraped off the surface of the plate with a sterile glass rod bent at a right angle, washed three times in physiological saline $(0.85 \% \mathrm{Na} \mathrm{Cl})$ and finally suspended in $25 \mathrm{ml}$ thereof. A heavy suspension was obtained which, when diluted 50 times, had an optical density of 0.7 in case of Staph. aureus and the micrococcus and 0.4 in case of Staph.epidermidis. Extinction was read in a Unicam SP 600 spectrophotometer at $600 \mathrm{~nm}$. The organisms were killed by heat at $65^{\circ} \mathrm{C}$ for 30 minutes in a water bath and then plated for sterility before use.

IMMUNIZATION

Before inoculation a pre-immune bleed of $10 \mathrm{ml}$ of blood was taken from each rabbit which was thereafter rested for one week. The serum from these blood samples was separated and kept frozen as a control to test for natural antibodies against staphylococci and micrococci. The rabbits were each challenged with a dose of $0.5 \mathrm{ml}$ of the vaccine intravenously; two rabbits were used for each vaccine. After an interval of one week each rabbit was given three doses of $1 \mathrm{ml}$ each intravenously on three successive days of the week for eight weeks. 
The rabbits were bled on the ninth week; $50 \mathrm{ml}$ of blood was taken from each, the serum was separated and kept frozen until use. After a rest period of four weeks a course of immunization of four weeks was repeated for raising more serum.

The titre of the sera (after absorption, see below) with their respective vaccine strains was $1 / 512$ in case of Staph. aureus antiserum, 1/64 in case of Staph. epidermidis antiserum, and $1 / 128$ in case of micrococcus antiserum.

\section{ABSORPTION OF SERA}

Each antiserum was absorbed separately with each of the other two vaccine strains. Absorption was done by mixing 2 volumes of serum with 1 volume of packed and killed cells. The mixture was left at room temperature for three hours with frequent shaking and then overnight in the refrigerator. The serum was recovered by centrifugation. The absorbed sera were tested by slide agglutination with each of the three vaccine strains to test the efficiency of absorption. One absorption was enough to render the serum non-reactive with the absorbing strain. Overall nine sera were thus available for testing, the three non-absorbed sera and the six absorbed (table I).

\begin{tabular}{|c|c|c|c|c|c|c|c|}
\hline \multirow[t]{2}{*}{ Serum } & \multirow[t]{2}{*}{ Absorbed with } & \multicolumn{3}{|c|}{ Agglutination of } & \multicolumn{3}{|c|}{ Precipitation of } \\
\hline & & $S I$ & $S I I$ & $M$ & $S I$ & $S I I$ & $M$ \\
\hline & None & $\div$ & - & + & + & + & - \\
\hline & II & + & - & + & $\doteq$ & - & - \\
\hline & & + & - & - & + & - & - \\
\hline & None & $\div$ & + & - & $\div$ & $\div$ & - \\
\hline \multirow[t]{3}{*}{ II } & I & - & + & - & - & - & - \\
\hline & & $\perp$ & + & - & - & $\div$ & - \\
\hline & None & + & - & + & $\div$ & - & $\div$ \\
\hline \multirow[t]{2}{*}{$\mathbf{M}$} & I & - & - & + & - & - & - \\
\hline & II & + & - & + & $\div$ & - & $\div$ \\
\hline
\end{tabular}

Table I Reactions of sera with the vaccine strains

SI = staphylococcus, Baird-Parker subgroup I (Staph. aureus) SII = staphylococcus, Baird-Parker subgroup II

$\mathbf{M}=$ micrococcus

\section{SEROLOGICAL REACTIONS}

The undiluted sera were used to test the strains by slide agglutination and in 31 strains by precipitation as well.

For agglutination, 2-3 loopfuls of the strain grown on nutrient agar overnight were suspended in $0.2 \mathrm{ml}$ of physiological saline in a $3 \times \frac{1}{2}$ in. tube. Using a pasteur pipette the bacteria were mixed thoroughly and two separate drops were placed on a clean microslide. A loopful of serum was mixed with one of the drops (the other served as a control) and the slide was rocked for a few seconds and observed for agglutination.

The saline suspensions of the vaccine strains and 31 other strains were treated with trypsin and retested: one drop of a $1.5 \%$ solution of trypsin (Difco trypsin powder 1:250, code no. B152) was added to the saline suspension. The $\mathrm{pH}$ was adjusted to 8.2 using a $\mathrm{BDH}$ Universal indicator. The suspension was then incubated at $37^{\circ} \mathrm{C}$ for two hours and then used for testing as above.

For precipitation bacterial extracts were used as antigens. Extraction was done in physiological saline, $0.2 \mathrm{~N} \mathrm{HCl}$, and a $5 \%$ solution of trichloracetic acid: the growth from a $9 \mathrm{~cm}$ agar plate was suspended in $0.4 \mathrm{ml}$ of each of these solutions in $3 \times \frac{1}{2}$ in tubes and thoroughly mixed on a whirlmixer. The tubes were placed in a boiling water bath for 10 minutes and then removed and allowed to cool. One drop of a $0.02 \%$ phenol red indicator was added to the acid extracts which were neutralized carefully with $0.5 \mathrm{~N}$ and $0.2 \mathrm{~N} \mathrm{NaOH}$. The clear supernatant obtained by centrifugation was used as the extract.

Mild extraction was also performed by a slow method at $56^{\circ} \mathrm{C}$ for two hours aiming at gentle treatment of the antigen(s) concerned.

To perform the precipitation reaction a capillary tube was used to place 1 drop of serum in the central well of the gel diffusion medium (see above) and 1 drop of extract in each of the peripheral wells. The slides were left in a moist chamber at room temperature for 24 to 48 hours and then examined for precipitation lines.

TESTS FOR THE ANAEROBIC FERMENTATION OF GLUCOSE

This was done by the method recommended by the Subcommittee on the Taxonomy of Staphylococci and Micrococci (International Bulletin of Bacteriological Nomenclature and Taxonomy, 1965). Doubtful results were often obtained and in these cases the test was repeated once by the same method in parallel with another method which we have used on several hundreds of strains before. In this method the same medium recommended by the subcommittee was used but the agar concentration was increased to $1.2 \%$. The medium was dispensed in repli-dishes (Dyos Plastics Ltd, Surbiton, Surrey). These were $10 \times 10 \mathrm{~cm}$ square plastic plates divided into 25 equal squares. Each square was filled with $2 \mathrm{ml}$ of medium which was left to solidify. One drop of an overnight broth culture of each strain was placed in one of the squares. The whole plate was incubated anaerobically in a McIntosh and Fildes jar for five days and then read. This test was found helpful in confirming doubtful results obtained by the subcommittee method. 
PHAGE TYPING

A set of 19 phages, kindly supplied by Professor R. E. O. Williams, was used for typing all the 176 strains. The method of typing was essentially similar to that used for coagulase-positive staphylococci (Blair and Williams, 1961). Typing was done at 100 RTD.

\section{Results}

Unabsorbed sera when tested with the vaccine strains were somewhat non-specific, specially by agglutination. Treatment of the cells with trypsin was done on the assumption that this enzyme may remove by digestion possible surface blocking antigens or non-specific protein antigens. It was found, however, that this treatment increased the tendency to cross-reactivity. For this reason agglutination was performed with untrypsinized saline suspensions.

As shown in table I, at least one absorbed serum reacted specifically with its homologous vaccine strain by agglutination and precipitation. However, when the precipitation technique was applied to test the rest of the strains it was found in the 31 strains tested that only few reacted with the sera by this method. All 176 strains were therefore tested by agglutination only using a saline suspension of each strain against both Staph. epidermidis and micrococcus absorbed antisera. Staph. aureus antiserum was not used in testing this group of strains. Table II shows a comparison between the results of biochemical and agglutination tests in distinguishing coagulasenegative staphylococci from micrococci. Of 113 strains classified biochemically as staphylococci, 99 reacted with the Staph. epidermidis antiserum alone, seven with the micrococcus antiserum, and seven with neither. Of 63 micrococci, 55 reacted with the micrococcus antiserum, none with the Staph. epidermidis antiserum, and eight with neither. Thus 161 of the 176 strains $(91 \%)$ were classified serologically and in 154 of the 161 instances $(95 \%)$ the results of the serological and biochemical classification were in agreement. None of the strains tested

\begin{tabular}{|c|c|c|c|c|}
\hline \multirow[t]{2}{*}{ Biochemically } & \multicolumn{3}{|c|}{ Serologically } & \multirow[t]{2}{*}{ Total } \\
\hline & $S$ & $M$ & No Reaction & \\
\hline $\mathbf{S}$ & 99 & 7 & 7 & 113 \\
\hline $\mathbf{M}$ & 0 & 55 & 8 & 63 \\
\hline Total & 99 & 62 & 15 & 176 \\
\hline
\end{tabular}

Table II Biochemical and serological classification of coagulase-negative staphylococci and micrococci

$\mathbf{S}=$ staphylococci: $\mathbf{M}=$ micrococci

reacted with the two sera at the same time. None of the strains diagnosed biochemically as micrococci was mistaken serologically as staphylococci. Table III shows the classification of the strains from different sources and their ability to be typed by the coagulase-negative phages. In the case of the staphylococci, if we rely on the serological test alone for selection of strains before typing, it is seen that 57 out of 99 strains $(57 \%)$ were typable. If, on the other hand, we rely on the biochemical test alone 61 out of 113 strains $(54 \%)$ would be typable. The difference between the two percentages was not statistically significant. It is noted also from this table that about $19 \%$ of micrococci were typable by these phages. Table IV shows the number and percentage of strains of staphylococci diagnosed by serology from different sources which were typable by the phages. The percentage of strains that could be phage typed among nasal staphylococci was significantly higher than those from the other sources combined $(\mathrm{P}<0.005)$.

The 15 strains which did not react with these two

\begin{tabular}{|c|c|c|c|}
\hline \multirow{2}{*}{$\begin{array}{l}\text { Source } \\
\text { Nose }\end{array}$} & \multirow{2}{*}{$\begin{array}{l}\text { Number } \\
\text { Serologically } \\
\text { Staphylococci } \\
38\end{array}$} & \multicolumn{2}{|c|}{$\begin{array}{l}\text { Number (and Percentage) } \\
\text { Phage Typable }\end{array}$} \\
\hline & & 32 & (84) \\
\hline Urine & 11 & $5)$ & \\
\hline Shunt & 26 & $12 \succ 25$ & (41) \\
\hline Blood & 24 & 8 & \\
\hline
\end{tabular}

Table IV Phage typability of coagulase-negative staphylococi $i$

\begin{tabular}{|c|c|c|c|c|c|c|c|}
\hline \multicolumn{2}{|l|}{ Classification } & \multirow{2}{*}{$\begin{array}{l}\text { Number } \\
\text { Examined }\end{array}$} & \multicolumn{4}{|c|}{ Isolated from } & \multirow{2}{*}{$\begin{array}{l}\text { Phage } \\
\text { Typable }\end{array}$} \\
\hline Biochemical & Serological & & Nose & Urine & Shunt & Blood & \\
\hline $\mathbf{S}$ & $\mathrm{S}$ & 99 & 38 & 11 & 26 & 24 & 57 \\
\hline $\mathbf{S}$ & $\mathbf{M}$ & 7 & 2 & 0 & 1 & 4 & 2 \\
\hline $\mathbf{S}$ & - & 7 & 5 & 0 & 1 & 1 & 2 \\
\hline $\mathbf{M}$ & $\mathbf{M}$ & 55 & 15 & 25 & 1 & 14 & 10 \\
\hline $\mathbf{M}$ & $\mathbf{S}$ & 0 & 0 & 0 & 0 & 0 & 0 \\
\hline $\mathbf{M}$ & - & 8 & 1 & 5 & 1 & 1 & 0 \\
\hline
\end{tabular}

Table III Classification, origin, and phage typability

$\mathbf{S}=$ staphylococci; $\mathbf{M}=$ micrococci; $-=$ non-reactive with the sera 
sera did not show special cultural characters, were all except two non-typable by the coagulasenegative phages, and none of them was typable by the coagulase-positive phages. None was also agglutinated with Staph. aureus antiserum. Twenty strains of Staph. aureus were tested with all absorbed sera. Two did not react with any, 12 reacted only with Staph. aureus antiserum absorbed with micrococcus, six reacted with Staph. aureus antiserum absorbed with micrococcus as well as with micrococcus antiserum absorbed with SII but not with micrococcus antiserum absorbed with Staph. aureus. This shows the importance of testing for coagulase to exclude Staph. aureus.

\section{Discussion}

The advantages of a simple slide agglutination test to distinguish coagulase-negative staphylococci from micrococci are obvious. It was found that $91 \%$ of the strains examined were classifiable into either genus by this test. In $95 \%$ of cases the results of the serological and biochemical classification were in agreement. The biochemical test, however, requires five days' incubation to give an answer and the results are often not clear-cut. None of the pre-immune sera of rabbits showed natural antibodies to Staph. epidermidis or micrococci, although all the preim mune sera reacted with the Staph. aureus vaccine strain. Natural antibodies to Staph.aureus are known to occur in different breeds of rabbit and can result in difficulties in serological typing of Staph. aureus (Oeding, 1960). Such difficulty was not encountered in the present work in the case of coagulase-negative staphylococci and micrococci.

It was hoped to use precipitation instead of agglutination to distinguish staphylococci from micrococci as it is believed that the major antigenic difference between the two lies in a polysaccharide antigen which has a different teichoic acid composition in the two genera (Morse, 1963; Davison and Baddily, 1964; Baddily et al, 1968; Grov and Helgeland, 1971) and polysaccharide antigens are known to react more specifically by precipitation. The antisera prepared reacted specifically after absorption with the homologous vaccine strains but failed to react with the majority of 31 strains tested. The reasons for this were not investigated but it is possible that the immunized rabbits did not produce enough antibodies against the polysaccharide antigens, a condition which has been encountered by other workers in preparing antisera to Staph. aureus (Julianelle and Weighard, 1934, 1935). Alternatively the method of extraction used was not adequate in extracting the antigens concerned from the strains. More gentle extraction at $56^{\circ} \mathrm{C}$ for two hours instead of boiling was not su ccessful either. However, the specific reactions obtained by agglutination in $91 \%$ of the strains with the absorbed sera fulfilled the object of the present study to distinguish staphylococci from micrococi to a great extent. No attempt was made to differentiate staphylococci or micrococci into serological subgroups corresponding to Baird Parker's (1963) biotypes. Such an attempt was not rewarding, as reported by Hasselgren and Oeding (1972), who examined 40 strains of micrococci representing the eight subgroups of BairdParker and found that these cocci have a number of agglutinogens without any systematic pattern. The majority of the agglutinogens were shared by many strains irrespective of biochemical type and no agglutinogens were characteristic of any biochemical subgroup. They added that strains of the same biochemical type were not more related antigenically than strains of different types. In the case of staphylococci Bayston (1972) found that sera of children with colonized Spitz-Holter valves have antibodies in high titre to one strain of coagulasenegative staphylococcus of 'subtype SII A'. He also examined a large number of strains and types of Staph. albus and found that they were all agglutinated by one immune serum. The findings of these authors as well as those in the present work suggest that there are possibly antigenic determinant(s) common to all Staph. epidermidis strains which are distinct from other determinant(s) common to all micrococci irrespective of their biochemical subgrouping.

Agglutination would be a useful quick screening test for sorting out staphylococci from micrococci, a procedure highly desirable before phage typing as it is known that the phages concerned act mainly on staphylococci (Verhoef et al, 1971a and b, 1972; Dean et al, 1973). Using agglutination as a screening test would not result in missing strains for typing as it was found that the percentage of typable staphylococci after biochemical did not differ statistically from that after serological screening.

I am deeply indebted to Dr M. T. Parker for continued encouragement and advice. I am grateful to Dr A. G. Towers, Dr N. Mortensen, Dr R. J. Holt, and to all pathologists in hospital laboratories for supplying the strains. I also wish to thank Professor R. E. O. Williams for the generous supply of phages.

\section{References}

Baddiley, J., Brock, J. H., Davison, A. L., and Partridge, M. D. (1968). The wall composition of micrococci. J. gen. Microbiol., 54, 393-396.

Baird-Parker, A. C. (1963). A classification of micrococci and staphylococci based on physiological and biochemical tests. J. gen. Microbiol., 30, 409-427.

Bayston, R. (1972). Serological investigations in children with colonized Spitz-Halter valves. J. clin. Path., 25, 718-720. 
Blair, J. E., and Williams, R. E. O. (1961). Phage typing of staphylococci. Bull. Wld Hlth Org., 24, 771-784.

Chalmers, A. (1972). A modification of the oxidation/fermentation test for the classification of Micrococcaceac.J.med. Lab. Technol. 29, 379-384.

Davison, A. L., and Baddiley, J. (1964). Glycerol teichoic acids in walls of Staph. epidermidis. Nature (Lond.), 202, 874.

Dean, B. A., Williams, R. E. O., Hall, F., and Corse, J. (1973). Phage-typing of coagulase-negative staphylococci and micrococci. J. Hyg., in press.

Evans, J. B., Bradford, W. L., Jr., and Niven, C. F., Jr. (1955). Comments concerning the taxonomy of the genera Micrococcus and Staphylococcus. Int. Bull. bact. Nomencl., 5, 61-66.

Grov, A., and Helgeland, S. M. (1971). Immunochemical characterization of Staph.epidermidis and Micrococcus cell walls. Acta path. microbiol. scand., Sect. B, 79, 812-818.

Hasselgren, I. L., and Oeding, P. (1972). Antigenic studies of genus Micrococcus. I. Agglutination. Acta path. microbiol. scand., Sect., B, 80, 257-264.

Holt, R. J. (1969). The classification of staphylococci from colonized ventriculo-atrial shunts. J. clin. Path., 22, 475-482.

Holt, R. J. (1972). The pathogenic role of coagulase-negative staphylococci. Brit. J. Derm., 86, Suppl. 8, 42-47.

Julianelle, L. A., and Weighard, C. (1934). Immunological specificity of carbohydrates derived from staphylococci. Proc. soc. exp. Biol. (N.Y.), 31, 947-949.

Julianelle, L. A., and Weighard, C. W. (1935). The immunological specificity of staphylococci. I. The occurrence of serological types. J. exp. Med., 62, 11-21.

Mabeck, C. E. (1969). Studies in urinary tract infections. II. Urinary tract infections due to coagulase-negative staphylococci. Acto med. scand., 186, 39-45.
Morse, S. I. (1963). Isolation and properties of a group antigen of Staph. albus. J. exp. Med., 117, 19-26.

Mortensen, N. (1969). Studies in urinary tract infections. III. Biological characteristics of coagulase-negative staphylococci associated with urinary tract infections. Acta med. scand., 186, 47-51.

Nakhla, L. S., Al-Hussaini, M. K., and Shokeir, A. A. W. (1970). Acute bacterial conjunctivitis in Assiout, Upper Egypt: a oneyear study. Brit. J. Ophthal., 54, 540-547.

Oeding, P. (1960). Antigenic properties of Staphylococcus aureus, Bact, Rev., 24, 374-396.

Quinn, E. L., Cox, F., and Fisher, M. (1965). The problem of associating coagulase-negative staphylococci with disease. Ann. N.Y. Acad. Sci., 128, 428-442.

Public Health Laboratory Service (1971). Meningitis due to Staph. albus. Communicable Disease Report, P.H.L.S., 71/35 pp. 1112.

International Bulletin of Bacteriological Nomenclature and Taxonomy (1965). Subcommittee on the Taxonomy of Staphylococci and Micrococci Recommendations. Int. Bull. bact. Nomencl., 15, 109-110.

Verhoef, J., Van Boven, C. P. A., and Winkler, K. C. (1971a). Lysogeny in coagulase-negative staphylococci. J. med. Microbiol., 4, 405-412.

Verhoef, J., Van Boven, C. P. A., and Winkler, K. C. (1971b). Characters of phages from coagulase-negative staphylococci. J. med. Microbiol., 4, 413-424.

Verhoef, J., Van Boven, C. P. A., and Winkler, K. C. (1972). Phage typing of coagulase-negative staphylococci. J. med. Microbiol., $5,9-19$.

Watanakunakorn, C., and Hamburger, M. (1970). Staphylococcus epidermidis endocarditis complicating a Starr-Edwards prosthesis. Arch. intern. Med., 126, 1014-1018. 